\title{
JUVENTUD NEGADA Y NEGATIVIZADA: Representaciones y formaciones discursivas vigentes en la Argentina contemporánea
}

\author{
El resultado era que el carácter principal de la condi- \\ ción juvenil rehuía constantemente el análisis de los \\ expertos: la percepción social nunca había expresado \\ el polimorfismo que, sin embargo, era el elemento más \\ significativo de la experiencia social de los jóvenes. \\ LUISA PASSERINI, 1996:437.
}

MARIANA CHAVES*

\section{RESUMEN}

En este artículo se brinda una descripción y análisis de las representaciones y discursos vigentes acerca de las y los jóvenes en la Argentina urbana contemporánea. Esta caracterización fue construida con base al trabajo de campo con diversos actores (jóvenes, no-jóvenes, medios de comunicación) realizado entre los años 1998 y 2004 en la ciudad de La Plata (Provincia de Buenos Aires, Argentina) como parte de la investigación doctoral de esta autora (Chaves, 2005). El análisis de los discursos permitió identificar diversas representaciones sobre la juventud y reconocer formaciones discursivas en las que dichas representaciones entraban en juego. El escrito ofrece también una sistematización de caracterizaciones realizadas por otros autores para la juventud argentina y/o la juventud latinoamericana y se establecen equivalencias con la propuesta realizada. Finalmente se interpreta que las miradas hegemónicas sobre la juventud latinoamericana responden a los modelos jurídico y represivo del poder. Se sostiene que la juventud está signada por «el gran NO», es negada (modelo jurídico) o negativizada (modelo represivo), se le niega existencia como sujeto total (en transición, incompleto, ni niño ni adulto) o se negativizan sus prácticas (juventud problema, juventud gris, joven desviado, tribu juvenil, ser rebelde, delincuente).

Palabras Clave: Juventud, Discursos, Representaciones

* Antropóloga argentina, candidata a doctora FCNyM, UNLP. Becaria CONICET. Docente e investigadora Núcleo de Estudios Socioculturales, Facultad de Trabajo Social, Universidad Nacional de La Plata y de la Universidad Nacional de Tres de Febrero.

E-Mail: mchaves@fcnym.unlp.edu.ar. 


\title{
Juventude negada e negativizada: representações e formações discursivas vigentes na Argentina contemporânea
}

\section{RESUMO}

Este artigo apresenta descrição e análise das representações e discursos em vigor sobre os/as jovens na Argentina urbana contemporânea. Esta caracterização foi construída com base no trabalho de campo realizado com diversos atores (jovens, não-jovens, meios de comunicação), entre 1998 e 2004 na cidade de La Plata (Província de Buenos Aires, Argentina) como parte da pesquisa de doutorado desta autora (Chaves, 2005). A análise dos discursos permitiu identificar diversas representações sobre a juventude e reconhecer formações discursivas das quais estas representações faziam parte. O texto apresenta também uma sistematização de caracterizações realizadas por outros autores sobre a juventude argentina e/ou a juventude latino-americana, e são estabelecidas equivalências com a proposta apresentada. Finalmente, interpreta-se que os olhares hegemônicos sobre a juventude latino-americana correspondem aos modelos jurídicos e repressivos do poder. Sustenta-se que a juventude está marcada pelo "grande NÃO». É negada (modelo jurídico), ou negativizada (modelo repressivo). Nega-se ao jovem a existência como sujeito total (em transição, incompleto, nem criança, nem adulto), ou este tem suas práticas negativizadas (juventude problema, juventude cinza, jovem desviado, tribo juvenil, rebelde, delinqüente).

\section{Palavras chave: Juventude, Discursos, Representações}

Unfit and negative youth: current discursive formations and representations among the contemporary Argentina

\begin{abstract}
This article delivers an analysis and description of the current representations and speeches regarding the contemporary young people of Argentina. This representation was built based on the field job carried out with several actors (young people, old people, communications media) during years 1998 and 2004 in the city of La Plata (Province of Buenos Aires) as a part of the doctoral investigation of the authoress (Chaves, 2005). The analysis of the speeches allowed the identification of several representations over the young as well as the acknowledgement of discursive formations in which such representations were included. The note includes as well a systematization of characterizations for the young people of Argentina and/or Latin America,
\end{abstract}


carried out by other authors. As well, equivalencies are established with the offered proposal. Finally, it is interpreted that the hegemonic visions towards the young people of Latin America are due to the legislature juridic and restrictive model. It is said that the young people is known by the "great NO", it is unfit (according to the juridic model) or negative (according to the restrictive model); the young are not allowed to exist as a total entity (in transition, uncomplete, nor infant nor grown up) or their practices are condemned (they are problematic youths, uncommitted, rebels or delinquents and offenders).

\section{KEY WORDS: YOUNG, SPEECHES, REPRESENTATIONS}

\section{INTRODUCCIÓN}

Para identificar las formaciones discursivas vigentes acerca de la juventud se relevaron distintos discursos a partir de fuentes primarias y secundarias que pueden agruparse del siguiente modo: a) padres y madres (entrevistas); ${ }^{1}$ b) profesores, preceptores, directivos, propietarios de escuelas y miembros de los equipos de orientación escolar (entrevistas y encuentros de capacitación) ${ }^{2}$ c) industrias de la comunicación: medios gráficos (principalmente diario Clarín — nacionaly El Día - local-), programas radiales, televisivos y publicidades

1 Los padres y madres no fueron entrevistados solos, la información construida surge de la participación en las entrevistas de sus hijos. Esta situación se generaba en algunos casos por la presencia de los padres en la vivienda al momento de realizar la entrevista, fueron pocos los casos, pero el diálogo generado entre las dos generaciones fue útil (creo que sería interesantísimo y productivo para el estudio de grupos de edad realizar entrevistas grupales con miembros de distintas franjas etarias, pero esto iba más allá del objetivo de este trabajo).

2 Las entrevistas fueron realizadas en el marco del proyecto de investigación «Arquitecturas y espacios urbanos de jóvenes», dirigido por Daniel Pussó, con el objeto principal de indagar sobre los establecimientos educativos, pero como no faltó la referencia a los jóvenes pude utilizar ese material para identificar representaciones. Lo mismo sucedió con las experiencias de capacitación, he diseñado y dictado cursos o conferencias para la Dirección General de Cultura y Educación de la Provincia de Buenos Aires en los cuales siempre fue tema la juventud, por lo que he podido recabar también esos discursos. 
(relevamiento propio y fuentes secundarias); d) políticas públicas o sociales (análisis de documentos y fuentes secundarias); e) jóvenes (entrevistas).

Como resultado del análisis se observa que en el interior de cada grupo existe una diversidad de discursos que remiten a distintos modos de representar a la juventud, modos que se vinculan con distintas formaciones enunciativas.

Las representaciones sociales son una forma de conocimiento de lo cotidiano. Básicamente la noción de representación social está tomada de los desarrollos de Denise Jodelet (1986) desde la psicología social, para quien,

[Es un] conocimiento práctico. Al dar sentido, dentro de un incesante movimiento social, a acontecimientos y actos que terminan por sernos habituales, este conocimiento forja las evidencias de nuestra realidad consensual, participa en la construcción social de nuestra realidad (Jodelet, 1986).

Se han sumado la perspectiva constructivista de Thomas Berger y Peter Luckmann (1974) y el modo de pensar las formaciones discursivas que aportó Michel Foucault (1997). Este enfoque ha sido desarrollado también por otros miembros del núcleo de investigación en el que participo (Ceirano, 2000; Caggiano, 2000; Rodríguez, P., 1998). ${ }^{3}$ El análisis de discurso utilizado se basa en la metodología propuesta por Magariños de Morentin (1991 y posteriores) y continuada por los miembros del equipo antes citados. Para nuestro caso las representaciones funcionan como ejes conceptuales:

identificar los ejes conceptuales ordenadores, según los cuales pueden agruparse las definiciones obtenidas. Los conjuntos así constituidos son representativos de los distintos modos de atribuir significado a los correspondientes términos, por parte de la comunidad o sector social que produjo los discursos en estudio. La principal utilidad diferencial del método que aquí se propone es descubrir cuáles son las componentes y/o los rasgos prototípicos de determinados conceptos en estudio, tal como han sido utilizados en determinado momento por dicha comunidad (Magariños de Morentin, 2000a:5).

3 Varios trabajos se pueden consultar en la página del Núcleo de Estudios Socioculturales www.trabajosocial.unlp.edu.ar/nes. 
Las representaciones no resultaron exclusivas de un grupo de enunciadores del tipo A, B, C, D o E, sino más bien se trata de una diferencia de proporciones en los tipos de discursos en distintos grupos. En términos generales se hallan representaciones y discursos sobre la juventud que funcionan de manera «horizontal», si vale la imagen geométrica, es decir, operan como articuladores de sentido sobre lo juvenil desde varios ángulos, pero en comunión. Las diferencias y contradicciones no aparecen entre estos grupos sino entre discursos. Se organizaron entonces grupos por discursos, por clasificación del contenido de lo enunciado. No es que el sujeto enunciador ha desaparecido, sino que no es adecuado suponer un discurso social homogéneo para cada grupo social armado desde otro criterio: clase, género o profesión. Por ejemplo, el grupo E está constituido por jóvenes que son al mismo tiempo el objeto del discurso, y cuando ellos hablan sobre sí mismos acuden a los discursos vigentes (disponibles) ya sea para explicarse por oposición o para interpretarse en ellos, entonces, en mi perspectiva analítica, el discurso cobra fuerza. La clave no la coloco en quién está de un lado y quién del otro, sino en la existencia y operatividad del discurso en la sociedad y la cultura. Por lo tanto, las afirmaciones así como las negaciones del mismo son lo que lo hacen existir, siendo esto lo que posibilita constituir identificaciones, pertenencias, alianzas y oposiciones. Este es el clivaje del conflicto, que obviamente emerge montado en otros conflictos sociales: de clase, de generación, de género, de territorio, etc. (no siendo una enumeración por orden de prioridades).

\section{CARACTERIZACIÓN DE LA JUVENTUD}

\section{a) Representaciones}

Un conjunto de representaciones definen a los jóvenes a partir del ser en sí mismo. Ya en 1962 Henri Lefebvre avizoraba este carácter mítico de la representación juvenil,

El mito de la juventud, como el del proletariado (y los de la modernidad en general), consiste en una serie de afirmaciones filosóficas y de redundancias de orden ontológico, esto es, relativas a un 'ser' que se pretende definir. La juventud tendría su 'ser' propio y se la definiría por ella misma y para ella misma (Lefebvre, 1969:187, citado en Groppo: 2000:282). 
Se parte de una comparación con perspectiva adultocéntrica, la definición se hace por diferencia de grado en relación al parámetro elegido, lo que lleva a establecer características desde la falta, las ausencias y la negación, y son atribuidas al sujeto joven como parte esencial de su ser. Esta perspectiva conduce a perder de vista la condición juvenil como construcción social, quedando oculto bajo el manto de la naturalidad del fenómeno que estas concepciones son discursos altamente ideologizados y con perspectiva gravemente discriminadora. Su afirmación es una cuestión de naturaleza: se es joven de tal manera, y cuando se es joven se es inseguro, incompleto, peligroso, «lo que es en su propia naturaleza, en razón de su constitución, de sus rasgos de carácter o de sus variedades patológicas» (Foucault, 1993:262). Dentro de este campo de representaciones se identifican las siguientes.

i) Joven como ser inseguro de sí mismo: la comparación está establecida acá con aquellos que estarían seguros de sí mismos, o sea, los adultos. El joven es presentado como un ser inseguro de sí mismo y de los demás. Con este argumento se legitima la intervención sobre su vida, para mostrarle el camino, para hacer por él. Enfrentado a un modelo de adulto dueño de sí mismo, es decir seguro, cumplidor de las normas. La sociedad ha encontrado en la juventud el espacio social donde depositar al enemigo interno, el chivo expiatorio de los males sociales. ${ }^{4}$

ii) Joven como ser en transición: el momento de ser joven es presentado como el de transición por excelencia. Desde la infancia, se transita hacia la adultez que aparece como el momento de mayor plenitud, ya que luego sobreviene la decrepitud: la vejez. En las sociedades occidentales modernas la vida está simbolizada como una curva, se asciende hasta el punto culmine (adultez) y luego se desciende. El punto de partida (infancia) y el punto de llegada (vejez) son subordinados al punto medio. Si esta curva fuese coloreada y valorizada el

4 De acuerdo a Michel Foucault (tomado de Castro, 2003b) y Giorgio Agamben $(1998,2003)$ el paradigma del momento ya no es más el paradigma del disciplinamiento o de la normalización estrictamente, sino el paradigma de la seguridad; es en este contexto donde el sujeto joven puede ser leído, se convierte en el enemigo interno, porque es el que representa la inseguridad. ¿Pero no es contradictorio que el peligro esté representado por un ser inseguro? No, justamente su inseguridad es lo que lo encuadra en el paradigma, y es eso lo que lo hace peligroso. 
resultado sería: de la pureza a la impureza, de lo blanco —el nacimiento - a lo negro - la muerte- .

iii) Joven como ser no productivo: dado que el tiempo de la productividad es el tiempo del trabajo, particularmente del trabajo asalariado, el joven está lleno de tiempo libre, es un ser «ocioso». Los jóvenes son presentados como seres no productivos económicamente.

iv) Joven como ser incompleto: este joven inseguro, en transición y no productivo es un ser incompleto, le faltan cosas, va camino a ser completo=adulto. Por eso aparece el derecho a intervenir sobre él. Este razonamiento del ciclo de vida como competencia, en el sentido de una meta a lograr, ser adulto para luego retirarse, se articula perfectamente con la división social del trabajo que existe en las formaciones económicas capitalistas.

v) Joven como ser desinteresado y/o sin deseo: esta representación aparece con mucha fuerza en los ámbitos de socialización, circula ampliamente en las escuelas, en algunas familias y en todos los partidos políticos. La marcación del no deseo o el no interés está colocada en que no se desea/interesa por lo que se le ofrece. El rechazo, la indiferencia o el boicot hacia lo ofrecido - que es de interés para la institución, los padres, etc.- es leído como falta de interés absoluto, no como falta de interés en lo ofrecido. El no-deseo sobre el deseo institucional o familiar (ajeno a ellos) es tomado como no-deseo total, como sujeto no deseante. El joven queda así anulado por no responder a los «estímulos» y por lo tanto se refuerza la posición de enfrentamiento, ambas partes expresan «no ser comprendidas»: no les importa nada, no se interesan por nada, son apáticos y desinteresados, los llamas a hacer algo bueno y no vienen.

vi) Joven como ser desviado: en esa inseguridad de sí mismo, en esa transición, en ese ser incompleto, en esa no productividad y sin deseo, el joven aparece con una tendencia mayor que otros individuos a desviarse, tiene muchas posibilidades de desviarse del camino, porque sus objetivos no son claros y esto también lo hace ser un sujeto peligroso.

vii) Joven como ser peligroso: no es la acción misma, sino la posibilidad de la acción lo que lo hace peligroso. Todo joven es sospechoso, carga por su estatus cronológico la marca del peligro. Peligro para él mismo: irse por el mal camino, no cuidarse; peligro para su familia: trae problemas; peligro para los ciudadanos: molesta, agrede, es violento; peligro para LA sociedad: no produce nada, no respeta las normas. Hoy al Estado parece no interesarle fundamental-mente disciplinar, sin embargo, sí le interesa el mecanismo de seguridad: ya no importa 
que los chicos se porten mal, el problema es que son peligrosos.

viii) Joven como ser victimizado: aquel que no tiene capacidades propias será una víctima del acontecer social. Asimismo aquel que es todo en potencia, en posibilidad, pero que no puede SER porque no lo dejan, es aplastado, es dominado, está absolutamente oprimido, ese también será visto como víctima. Y hay un tercer espacio de la representación del joven víctima y es la justificación de los actos que entran en conflicto con la ley, la justificación de rupturas o quebrantos de la ley por su posición social de víctimas del sistema. A la víctima se suele acercarse desde la «comprensión» y la lástima, no desde el reconocimiento legítimo.

ix) Joven como ser rebelde y/o revolucionario: es la cualidad de joven como estado biocronológico lo que le otorga la capacidad de rebeldía y revolución, siendo de la adolescencia el ser trasgresor, enfrentarse a todos - parece ser que hay un desorden hormonal (pubertad) que posibilita un desorden social- . La tarea de la transformación social, la oposición o la protesta son su DEBER SER: ésa es la tarea de la juventud, el rol que cumplen en la sociedad y deben cumplir ese papel mientras sean jóvenes, si no lo hacen serán acusados de ineptos, de no cumplir su papel histórico predeterminado.

$\mathrm{x})$ Joven como ser del futuro: el joven es presentado como un ser de un tiempo inexistente. El pasado no le pertenece porque no estaba, el presente no le pertenece porque no está listo, y el futuro es un tiempo que no se vive, sólo se sueña, es un tiempo utópico. Ahí son puestos los jóvenes, y así quedan eliminados del hoy. Nunca pueden SER ELLOS jóvenes en el presente. El pasado es territorio de la juventud de los adultos de hoy. El presente es el tiempo de los adultos de hoy. Y el futuro es el país del nunca jamás. La espera es infinita, vana e ilusoria. Te roban el presente hipotecando el futuro. La promesa de un tiempo venidero donde hallarán completitud, donde el devenir biocronológico los hará seres completos, por lo que dejarán de ser jóvenes, y entonces su tiempo será el presente (del mañana claro está).

Otro modo en el que aparece esta representación es en el tan difundido eslogan de que los jóvenes de hoy no tienen futuro, o no les interesa el futuro o no tienen proyectos para el mañana. En esta demanda de proyecto para mañana suelen no leerse como proyecto las expectativas de futuro de los jóvenes (su tiempo utópico, sus sueños no tienen validez de proyecto), y sólo se espera - se acepta como respuesta válida - la repetición de una receta ya fracasada o un decir de memoria como funciona la reproducción del sistema social. 
Se está hablando del joven desde la potencialidad de la acción, no por lo que el joven es en relación a los demás, sino por lo que es $o$ puede ser en sí mismo. La interpretación del individuo por el individuo mismo.

\section{b) Formaciones discursivas}

Se han identificado distintas formaciones discursivas en las que se fundamentan estas representaciones, que se han agrupado en las siguientes.

i) Discurso naturalista: es aquel que define al joven o a la juventud como una etapa natural, como una etapa centrada en lo biológico, en la naturaleza, como una etapa universal (lo natural es universal). Se considera que la juventud existió desde siempre y de la misma manera, por lo que corresponde a la naturaleza biológica de los individuos.

ii) Discurso psicologista: es la mirada sobre la juventud como momento de confusión, como un proceso psicológico particular que debe resolver casi individualmente y que de todos modos lo va a resolver, porque como todo esto es una etapa, sí o sí se les va a pasar. Es la presentación del joven como adolescente. Este es el término con el que se van a referir a los jóvenes en el discurso psicologista (también en el psicológico, pero se debe confundir), como aquel que adolece de algo, como dolencia, como sufrimiento (acompañado por muchas referencias al discurso médico, al modelo de la medicalización).

iii) Discurso de la patología social: la juventud es el «pedazo» de la sociedad que está enfermo y/o que tiene mayor facilidad para enfermarse, para desviarse. Es un acercamiento al joven a partir de verlo como el portador del daño social. Es una mirada negativa, de «problema»: vamos a tratar sobre juventud, vamos entonces a hablar de alcoholismo, SIDA, tabaquismo, embarazo adolescente. Este discurso está plagado de términos médicos y biológicos y sus intervenciones son planteadas como soluciones a problemas que tienden a proponer curas, separar (para evitar el contagio) o extirpar (el daño debe ser eliminado). ${ }^{5}$

5 Para una crítica de este discurso se recomienda la lectura de Rosario Román (2000) sobre vivencias del embarazo en las jóvenes, principalmente los primeros capítulos donde realiza un excelente trabajo de deconstrucción del modelo de la «juventud problema». 
iv) Discurso del pánico moral: reproducido sistemáticamente por los medios, es aquel que nos hace acercar a los jóvenes a través del miedo, de la idea del joven como desviado y peligroso. El joven cumple en la sociedad el rol del enemigo interno o chivo expiatorio.

Para entender mejor cómo funciona el pánico moral conviene describir el modelo original llamado discreto: existe primero un evento dramático (ejemplo: enfrentamiento entre grupos), que genera inquietud pública, produciéndose una sensibilización sobre el tema a través de una campaña de emprendimiento moral seguida de una acción de control cultural. Esta mecánica funcionó en los tempranos años 60 en Inglaterra, pero una década después la secuencia estaba totalmente alterada, y es este modo el que llega a nuestros días y opera tan eficazmente en nuestra sociedad: primero se produce una sensibilización sobre el tema a través de un emprendimiento moral, se genera inquietud pública, se organizan acciones de control cultural, se identifican eventos dramáticos o, mejor dicho, se construyen eventos como dramáticos y así se justifica una acción intensificada de control cultural (CCCS Mugging Group, 1975, en Hall y Jefferson, 2000).

v) Discurso culturalista: se trata de mirar a la juventud como una cultura, una cultura aparte de los otros grupos de edad de la sociedad, como si un grupo de edad pudiera construir una cultura por sí mismo, siendo que un aspecto fundante de lo cultural es su necesidad y capacidad de ser trasmitido y reproducido en las generaciones siguientes. Se incluye en este discurso el muy de moda término de «tribu juvenil» sobre el que se vuelve más adelante. Otro modo del discurso culturalista es el señalado por Margulis y Urresti (1996:21) donde la representación de la juventud es construida exclusivamente sobre los signos juveniles de clase media y alta - principalmente en su característica de etapa de moratoria social-, lo cual lleva a pensar la juventud no sólo de forma homogénea sino como puro signo. Esta caracterización no se opone al uso que le doy al término en esta sección, ya que el trasfondo epistemológico de las dos representaciones: tribus juveniles y juventud como moratoria social son iguales, sobreimprimen lo simbólico frente al resto de lo social, uno como cultura distanciada, el otro como «la» forma de ser joven en la cultura.

vi) Discurso sociologista: es aquel que representa al joven como víctima: él es producto de todo lo que pasa en la sociedad y lo social es presentado como «suprahumano», más allá de las personas, por lo tanto es un sujeto que nada puede hacer. La explicación está puesta en el afuera. El joven es una víctima de la globalización, de la sociedad 
moderna, del posmodernismo, de los medios de comunicación, del sistema escolar que no funciona, de los malos profesores. Estas representaciones articulan un discurso que también quita agencia al joven. Su calidad de actor social creador está anulada por la imposibilidad que tendrá de generar otro camino que no sea el que le estaba previsto a su sector social, si es pobre será ladrón, no les queda otra que salir a robar, la droga es la única salida de estos pibes de barrio periférico.

Todos estos discursos quitan agencia (capacidad de acción) al joven o directamente no reconocen (invisibilizan) al joven como un actor social con capacidades propias - sólo leen en clave de incapacidadesLas formaciones presentadas operan como discursos de clausura: cierran, no permiten la mirada cercana, simplifican y funcionan como obstáculos epistemológicos para el conocimiento del otro. Se trata de discursos que provocan una única mirada sobre el joven, pero que son utilizados estratégicamente -o políticamente- según sea de ricos o de pobres. Según sea la clase o sector de clase será el estereotipo a fijar, así se encuentran principalmente discursos naturalistas, psicologistas y culturalistas ligados a la juventud de clase media y alta, y discursos de patología social y pánico moral cuando se habla de la clase media empobrecida y los pobres. Tanto en sus versiones de «derecha» como de «izquierda» - o progresistas y neoliberales para usar términos de los noventa-, estas son miradas estigmatizadoras de la juventud. Desde la representación negativa o peyorativa del joven, como de su aparente extremo opuesto, la representación romántica de la juventud, son miradas que niegan. Las prácticas de intervención paternalistas no entran en contradicción con ninguno de estos discursos, todos le son útiles y unidos son más eficaces.

\section{CARACTERIZACIONES DE OTROS}

Varios autores han realizado caracterizaciones de discursos o teorías acerca de la juventud argentina y latinoamericana, ofrezco a continuación una breve síntesis del material revisado y una tabla donde se marcan equivalencias o semejanzas (puntos de contacto) entre las distintas caracterizaciones, incluida la propuesta en este estudio (véase tabla 1).

En orden cronológico de publicación, uno de los primeros trabajos es el realizado por Cecilia Braslavsky en 1986, quien ofrece una clasificación de discursos sobre la juventud titulando mito de la ju- 
ventud homogénea al mecanismo por el cual se identifica a todos los jóvenes con algunos de ellos y se presenta a toda la juventud como un conjunto monocromático de personas. Usando los colores como metáforas, la autora habla de tres interpretaciones que participan de este mito: la juventud dorada, gris y blanca. ${ }^{6}$

La manifestación dorada del mito de la juventud homogénea identifica a todos los jóvenes con los privilegiados - despreocupados o militantes en defensa de sus privilegios-, con los individuos que poseen tiempo libre, que disfrutan del ocio, y todavía más ampliamente, de una 'moratoria social', que les permite vivir sin angustias ni responsabilidades. La interpretación de la juventud gris hace a todos los jóvenes depositarios de todos los males. Transforma conceptualmente a la juventud en el grupo que más sufre los embates de las crisis, que más afectado está por la herencia de los hábitos y prácticas de la sociedad autoritaria. Los jóvenes serían la mayoría entre los desocupados, los delincuentes, los pobres, los apáticos. Ellos serían la desgracia y la resaca de la sociedad argentina, aunque se la presente irónicamente como 'grupo social privilegiado'.

[...] la interpretación de la juventud blanca ve en ella al Mesías, al Redentor, a los personajes maravillosos y puros que salvarían a la Humanidad de la entropía, que podrían hacer todo lo que no hicieron sus padres, incluso construir una Argentina democrática. Ellos serían los participantes, los éticos (Braslavsky, 1986:13, cursivas mías).

En 1993 Mariela Macri y Solange Van Kemenade publicaron Estrategias laborales de jóvenes en barrios carenciados. Allí realizan un examen de las perspectivas históricas y teóricas sobre juventud utilizadas en las sociedades europeas y americanas del norte y delimitan cinco paradigmas.

i) Organicistas. Basado en la observación de indicadores que tienen que ver con transformaciones biopsíquicas, estas teorías explican el origen de la juventud en la evolución de lo corpóreo, y formulan interpretaciones de tipo individualista. Partiendo que la edad es el único aspecto común en todas las sociedades, la toman como categoría central de explicación, y llegan a la conclusión que lo característico de la juventud es la no correlación entre lo físico y lo psíquico (cuerpo de adulto y psique de niño).

6 Esta clasificación ha sido retomado también por Margulis y Urresti, 1996. 
ii) Sociopsicológicas. La adolescencia es explicada desde esta perspectiva como una fase traumática marcada por la rebelión.

iii) Culturalistas. Incluye aspectos socioculturales y su vinculación con la evolución de la organización social. Juventud como etapa dedicada a la preparación y a la adquisición del saber humano en cuanto a la reproducción de la vida.

iv) Estructural funcionalistas. Se incluyen teorías de la socialización continua. La juventud como etapa en la que a través de la socialización se produce la conciliación entre las necesidades de la sociedad de formar agentes para reproducir las estructuras vigentes y las necesidades del individuo de adquirir su desarrollo personal. [...] Adolescente rebelde como mito folklórico, no como agente social. El objetivo es formarse bien para cumplir el rol adulto. [...] En este período de adolescencia adquieren relevancia los grupos de pares y sus subculturas contestatarias son una protección contra las tensiones que se ejercen en el exterior y por lo tanto resultan funcionales [...].

v) Contextuales. Conceptualizan a la juventud desde una perspectiva ecológica y multidisciplinaria. La teoría del medio ambiente, la teoría de la acción de Habermas, la teoría sistémica y la teoría del ciclo vital, dan cuenta del fenómeno de la juventud a partir de la consideración de factores que vienen del entorno y que influyen en el desempeño de los roles. Nos hablan de formas de transición diferentes de acuerdo al medio ambiente y señalan los cambios que se producen en el ciclo vital en la sociedad industrial moderna. Desde esta perspectiva se rescata el valor de los enfoques multidisciplinarios, que superan las interpretaciones de tipo exclusivamente biológico, psicológico o cultural (Macri y Van Kemenade, 1993:17-21, síntesis y cursivas propias).

Homero Saltalamacchia ha trabajado la temática juventud en relación a Puerto Rico. En un trabajo titulado «Estigmas de juventud» revisa los perfiles temáticos de algunas investigaciones y encuentra que el principal abordaje es el de la juventud como problema, «muestra a una juventud desocupada, desertora escolar, drogadicta delincuente e ideológicamente conservadora», que se completa actualmente «con un nuevo rasgo: el de receptor pasivo de toda propuesta de consumo» (S/F, acceso 2004:9). A continuación el autor propondrá una actitud diferente para tratar los temas. 
Actitud en la cual la juventud sea visualizada de una manera diferente. i) No como 'problema' a ser resuelto, sino como impulso renovador que busca expresarse y experimentar sus propios caminos.

ii) No como receptor pasivo de las políticas públicas o privadas, sino como reactor.

Se busca, además, iniciar una línea de investigaciones que incorpore a los propios jóvenes (mediante iniciativas de co-investigación ) no como meros 'objetos de la investigación' sino, en la medida de lo posible, como actores de esa investigación (S/F, acceso 2004:12, cursivas del autor).

La investigadora costarricense Dina Krauskopf (2000) analiza las programaciones para la juventud y reconoce dentro de estas políticas la coexistencia y competencia de cuatro paradigmas para pensar la juventud. ${ }^{7}$

i) Adolescencia: periodo preparatorio. Los adolescentes son percibidos fácilmente como niños grandes o adultos en formación. Tal enfoque se sustenta en el paradigma que enfatiza la adolescencia como un período de transición entre la niñez y la adultez. Le corresponde la preparación para alcanzar apropiadamente el estatus adulto como la consolidación de su desarrollo. En dichos conceptos se aprecia un vacío de contenidos para la etapa propiamente tal.

ii) Juventud: etapa problema. Favorece la visión del período como crisis normativa: «la edad difícil» [...] La fragmentación programática de la juventud como problema se revela al definirla en relación

7 El investigador uruguayo Ernesto Rodríguez también ha analizado las políticas de juventud en Latinoamérica. Reconoce cuatro «modelos» a partir de observar principalmente tres ejes: ¿qué tema?, ¿para quiénes?, ¿cuándo?, así obtiene (no son excluyentes): a) educación y tiempo libre con jóvenes integrados y crecimiento económico (entre 1950 y 1980), b) control social de jóvenes movilizados en un marco de crecientes tensiones (origen en los 60), c) enfrentamiento de la pobreza y el delito en un marco de crisis generalizada (80) y d) inversión en capital humano en el marco de la transformación productiva (inicios de los noventa) (Rodríguez, 2002:47-51). José Antonio Pérez Islas retoma estos modelos y jugando con las palabras explica que el Estado mexicano ha mirado a los jóvenes como «divino tesoro» en los 50 , como «divino problema» en los 60, como «divina desconocida» en los 70, como «divina delincuente» en los 80 y finalmente como «divino desmadre» en los 90 (Pérez Islas, 2000:212). 
al embarazo, la delincuencia, las drogas, la deserción escolar, las pandillas, etc. Se construye una percepción generalizadora a partir de estos polos sintomáticos y problemáticos. [...] A esto puede agregarse que el énfasis en el control favorece la estigmatización criminalizante de la juventud.

iii) Juventud: actor estratégico del desarrollo. Este enfoque destaca a la juventud como actor protagónico en la renovación permanente de las sociedades, particularmente en el contexto de la reestructuración socioeconómica y la globalización. Da un valor prominente a la participación juvenil como parte crucial de su desarrollo.

iv) Juventud ciudadana. En la segunda mitad de este siglo se crean las condiciones para establecer, de modo claro y explícito, que los niños y adolescentes tienen derecho a la ciudadanía. [...] El enfoque de derechos abandona el énfasis estigmatizante y reduccionista de la juventud como problema. La integración del paradigma que la señala como actor estratégico, con el paradigma de juventud ciudadana permite reconocer su valor como sector flexible y abierto a los cambios, expresión clave de la sociedad y la cultura global, con capacidades y derechos para intervenir protagónicamente en su presente, construir democrática y participativamente su calidad de vida y aportar al desarrollo colectivo (Krauskopf, 2000:3-6, cursivas de la autora, síntesis propia).

El cientista social boliviano Huáscar Cajías (1999) aborda las estigmatizaciones producidas sobre los jóvenes al comprobar un corrimiento de una visión idilica de la juventud hacia una visión de "generación problema». Identifica diferentes tipos de estigmas.

i) Aquellos originados en el mundo conservador. Discurso que busca al menos controlar la fuerza subvertora del orden establecido de la cual es - o puede ser- portadora una nueva generación emergente. Aquí se juzga al joven como irrespetuoso y se lo subestima desde la perspectiva de la experiencia.

ii) Aquellos con un destino focalizado. Las «víctimas propiciatorias» son preferentemente sectores de la juventud pobre (aunque mucho de este comportamiento no les caracterice). Son juzgados como portadores de la violencia callejera, de la ignorancia, de la vagancia. Permiten, incluso en casos de crecimiento extremo del estigma, ser el botón de muestra para juzgar a toda una generación. Hay otro tipo de focalización - sobre todo en sociedades con diversidad cultural y en 
las que las formas tradicionales de vida son arrinconadas por la modernidad - y es el juicio que pesa sobre la nueva generación de abandonar los valores y prácticas del ancestro.

iii) Aquellos provocados $u$ originados por un comportamiento juvenil contrario al «proceso humano». Más allá de los ajustes y fricciones intergeneracionales, la memoria larga permite identificar roles y comportamientos que toda generación joven debe cumplir para con el conjunto de la sociedad y su desenvolvimiento histórico; por tanto aquí se juzgaría a la juventud por su incumplimiento con la humanidad, por decirlo de alguna manera.

iv) Aquellos provocados por políticas de Estado. El origen del suceso no es el propio joven, siendo que éste «apenas» se limita a reaccionar ante determinadas presiones provenientes del desarrollo social. El poder determina, provoca o al menos sienta las bases de los comportamientos «buenos»y «malos» del joven para luego estigmatizar aquellos cuyo juzgamiento como negativo también él promueve.

v) Aquellos apoyados en su condición de ser el «otro». La pregunta, en este caso es si la sociedad es capaz de reconocer sus propias responsabilidades o si, más bien, la juventud funge de chivo expiatorio para explicar fracaso o pérdidas de perspectiva histórica. Muchas veces, por ejemplo, se le atribuye a la juventud una extendida apatía política; cierta o no, lo que pocas veces se incorpora es el análisis de la «pedagogía» política que reciben del mundo adulto. Para ir un poco más lejos, si asumimos que la juventud es una suerte de «reproducción ampliada» del proceso social, el incumplimiento de este rol puede deberse a condiciones propias de los jóvenes como a la incapacidad de las generaciones precedentes de sentar las bases de un desarrollo determinado. En este caso, se estigmatiza a la juventud con todas las formas y vertientes de la inviabilidad histórica que pueda estar pesando sobre la sociedad (Cajías, 1999:111-112, cursivas del autor, síntesis propia).

vi) Ética de la víctima: mendicidad y criminalidad. Se incluyen una serie de prácticas sustentadas en una suerte de «derecho de cobro», que el autor ve emerger con posterioridad a los discursos y prácticas de denuncia que conmocionaron una etapa de América Latina, de los que uno de sus resultados fue la identificación de la víctima y de sus derechos conculcados. De allí se legitiman estas prácticas que él caracteriza como aberrantes. Por un lado la mendicidad «caracterizado por extender la mano para que otro otorgue el derecho que uno es incapaz de construir y defender» y la criminalidad, «una suerte de bandolerismo juvenil 
- la equidad asumida por mano propia - supuestamente justificada por las condiciones de sometimiento y marginalidad a las que la sociedad las somete, pero absolutamente desconectada de un sentimiento globalizador que permita superar no sólo el problema individual sino del grupo social al cual se pertenece» (1999:115).

Por último Rossana Reguillo muestra brevemente los rostros estereotipados de los jóvenes latinoamericanos. ${ }^{8}$

En América Latina cuando los jóvenes se hicieron visibles en el espacio público, y sus conductas, manifestaciones y expresiones entraron en conflicto con el orden establecido desbordando el modelo de juventud que la modernidad occidental, en su 'versión' latinoamericana, les tenía reservado; fueron nombrados a fines de los 50 y durante los 60 como rebeldes, y como estudiantes revoltosos al finalizar esa misma década, pasando en los 70 a ser los subversivos, y en los 80 - cuando desaparecen de la escena política - serán adscriptos a la imagen del delincuente y luego del violento. Estos son los jóvenes visibilizados en la segunda mitad de siglo XX en América Latina (Reguillo, 2000).

\section{ConClusión}

Los puntos de contacto, semejanzas, equivalencias o diferencias entre las caracterizaciones expuestas y las representaciones y formaciones enunciativas presentadas por esta autora son graficadas en la tabla 1, allí se observa la variabilidad de términos que aplican los investigadores para

8 No pude dejar de asociar esta descripción con la que realiza Javier Auyero para el caso de los pobladores de villas miseria en Argentina, el autor dice, «Difícilmente uno pueda dar con una configuración urbana que haya sido (y aún sea) la depositaria de tantas (la mayoría de las veces malas) representaciones, de tantas esperanzas en el pasado y tantos miedos en el presente. Las villas fueron retratadas como el ejemplo acabado del fracaso del populismo peronista durante los años cincuenta, como suerte de laboratorios para los sueños modernizadores de los años sesenta, como cunas de la revolución en los setenta, como obstáculos para el progreso y como germinadores de subversión durante la última dictadura, como lugares de inmoralidad, crimen y ausencia de ley en la Argentina contemporánea. En la actualidad, la discusión pública sobre la inseguridad recurrentemente menciona a 'la villa' y 'los villeros' como una amenaza» (Auyero, 2001:20). Hagan el macabro juego de cambiar «villeros» por juventud y verán que da lo mismo. 
referirse casi a las mismas cosas. Es menester acordar conceptos dado que se hace innecesario y tedioso acarrear «tablas de equivalencias» como la que se ha construido. ${ }^{9}$ Segundo, y de otro orden, se ve cómo la gran coincidencia es en la marcación de fuerza que siguen teniendo todos los discursos de invisibilización y/o estigmatización de la juventud.

Se interpreta que las miradas hegemónicas sobre la juventud latinoamericana responden a los modelos jurídico y represivo del poder. Tomando la propuesta foucoultiana sostengo que la juventud está signada por "el gran NO», es negada (modelo jurídico) o negativizada (modelo represivo), se le niega existencia como sujeto total (en transición, incompleto, ni niño ni adulto) o se negativizan sus prácticas (juventud problema, juventud gris, joven desviado, tribu juvenil, ser rebelde, delincuente, etc.).

La apuesta teórica es pensar la juventud como relación, al joven como posibilidad, lo que incluye todas las caras, la posibilidad no es positiva en el sentido de «lo bueno» o «lo deseable», sino en el sentido del poder hacer, del reconocimiento de las capacidades del sujeto. Salirse de la medición de la normalidad. Elementos de esta concepción están presentes en las propuestas analíticas elegidas para sus investigaciones entre los autores revisados (ver última fila de la tabla 1). Todas estas versiones son de utilidad para el estudio de juventudes, cada una es emergente del momento y el motivo para el que fueron construidas (discursos del sentido común, discursos científicos, mediáticos, etc.). Los discursos son producciones situadas, tanto en el tiempo como en el espacio, jamás son inmutables, y responden a la negociación de todos los actores involucrados. La hegemonía de uno de los «tipos» de discurso sobre otro brinda indicios fuertes de cómo «la sociedad» (jóvenes incluidos) está pensando, se acerca y trata a sus miembros más jóvenes.

La Plata (Argentina), nOVIEMBre 2005

RECIBIDO: DICIEMBRE 2005

ACEPTADO: DICIEMBRE 2005

9 De ningún modo postulo mis términos como el parámetro, simplemente sucede que el trabajo sobre mi material empírico y los resultados obtenidos fueron previos al hallazgo de las clasificaciones de otros autores, fue así que en vez de cambiar los nombres de las representaciones y discursos decidí mostrar la variabilidad de las clasificaciones efectuadas desde diversas disciplinas y países (sistematización que no encontré previamente realizada). 


\section{REFERENCIAS BIBLIOGRÁFICAS}

Agamben, Giorgio (1998): Homo Sacer. Valencia: Pre-Textos.

- (2003): Stato di eccezione. Torino: Bollati Boringhieri.

AUYERO, JAVIER (2001): «Introducción. Claves para pensar la marginación». En Parias urbanos. Marginalidad en la ciudad a comienzos del milenio. Buenos Aires: Manantial.

Berger, Peter y ThOMAs LuckMANN (1974): La construcción social de la realidad. Buenos Aires: Amorrortu.

BRASLAVSKY, CECILIA (1986): La juventud argentina: informe de situación. Buenos Aires: CEAL.

Caggiano, Sergio (2000): «La insoportable levedad del sujeto. Modalidades enunciativas y construcción del sujeto. Una propuesta para operacionalizar su análisis». V Congreso de ALAIC, 26-29 abril, Santiago.

CAJÍAS, HUÁSCAR (1999): «Estigma e identidad. Una aproximación a la cuestión juvenil». Última Década $\mathrm{N}^{\circ} 10$. Viña del Mar: Ediciones CIDPA (disponible en www.cidpa.cl).

CAStro, Edgardo (2003a): «Notas sobre Stato di eccezione y Homo sacer II, I de Giorgio Agamben». Torino: Bollati Boringhieri. Ficha de cátedra seminario postgrado políticas del cuerpo, UNLP, La Plata.

_ (2003b): «Biopolítica y disciplina en Michel Foucault 1 y 2». Ficha de cátedra seminario postgrado políticas del cuerpo, UNLP, La Plata.

CeIRANO, VIRGINIA (2000): «Las representaciones sociales de la pobreza. Una metodología para su estudio». Revista MOEBIO N${ }^{\circ}$. Santiago: Universidad de Chile (disponible en www.rehue.csociales.uchile.cl).

Chaves, Mariana (2005): «Los espacios urbanos de jóvenes en la ciudad de La Plata». Tesis Doctoral, Facultad de Ciencias Naturales y Museo, UNLP, La Plata.

FouCAUlt, Michel (1997): La arqueología del saber. México: Siglo XXI.

_ (1993a): La vida de los hombres infames. Buenos Aires-Montevideo: Altamira-Nordan.

- (1993b): Genealogía del racismo. Buenos Aires-Montevideo: AltamiraNordan.

GROPPO, Luís ANTONIO (2000): Juventude. Ensayos sobre sociología e história das juventudes modernas. Rio de Janeiro: DIFEL.

Hall, StUART y TONY JeFFerson (eds.) (2000): Resistance Through Rituals: Youth Subcultures in Postwar Britain. London-New York: Routledge (1st published in 1975 as Working Papers in Cultural Studies $\mathrm{N}^{\circ} 7 / 8$. University of Birmingham: The Centre for Contemporary Cultural Studies).

JODELET, DENISE (1986): «La representación social: fenómenos, concepto y teoría». En Serge Moscovici: Psicología social 2. Buenos Aires: Paidós. 
KRAUSKOPF, DINA (2000): «Dimensiones críticas en la participación social de las juventudes». En SERGIO BALARDINI (comp.): La participación social y política de los jóvenes en el horizonte del nuevo siglo. Buenos Aires: CLACSO (disponible en www.clacso.edu.ar).

MACRI, MARIELA y SOLANGE VAN KEMENADE (1993): Estrategias laborales de jóvenes en barrios carenciados. Buenos Aires: CEAL.

MAGARIÑOS DE MORENTIN, JUAN A. (2000c) (editor): «Las operaciones de la semiótica general» Archivo de semiótica 1. Manual de estudios semióticos. (disponible en:

www.fortunecity.com/victorian/bacon/1244/Operaciones.html.

_ (2000b) (editor): «Encuadre semiótico de los proyectos de investigación». Archivo de semiótica manual de estudios semióticos.

(2000a): «Manual operativo para la elaboración de 'definiciones contextuales' y 'redes contrastativas'» (disponible en:

www.geocities.com/Athens/Academy/9962/manual.htm).

(1996): Los fundamentos lógicos de la semiótica y su práctica. Buenos Aires: Hachette.

_ (1992): «Fundamentos lógicos de la semiótica». En SEDIFRALE VIII, 1319 janvier, Santiago.

- (1991): «Esbozo semiótico para una metodología de base en ciencias sociales». Investigación $\mathrm{N}^{\circ} 6$. La Plata: Instituto de Investigación de la Comunicación Social, Escuela Superior de Periodismo y Comunicación Social, UNLP.

MARGULIS, M. Y URRESTI, M. (1996): «La juventud es más que una palabra». En MARIO MARGULIS (editor): La juventud es más que una palabra. Buenos Aires: Biblos.

PASSERINI, LUISA (1996): «La juventud, metáfora del cambio social (dos debates sobre los jóvenes en la Italia fascista y en los Estados Unidos durante los años cincuenta)». En LEVI y SCHMITT (comp.): Historia de los jóvenes. 2 tomos. Madrid: Taurus (disponible en www.cholonautas.edu.pe).

PÉREZ ISLAS, JOSÉ A. (2000): «Visiones y versiones. Jóvenes, instituciones y políticas de juventud». En MARTín-BARBERO y otros: Umbrales. Cambios culturales, desafios nacionales y juventud. Medellín: Corporación Región. También en Gabriel Medina (comp.) (2000): Aproximaciones a la diversidad juvenil. México: El Colegio de México.

Reguillo, Rossana (2000): Emergencia de culturas juveniles. Estrategias del desencanto. Buenos Aires: Norma.

Rodríguez, ERNeSTO (2002): Actores estratégicos para el desarrollo. Politicas de juventud para el siglo XXI. México: SEP-IMJ.

RodríGUEZ, PABLO GUSTAVO (2003): «N VIVO. Workbook». La Plata: mimeo.

- (2002): «La construcción ideológica de un estereotipo. Los hackers según la prensa argentina». La Plata: mimeo. 
(1998): «QSR NUD*IST 4. Guía de referencia rápida». La Plata: mimeo (disponible en http://analisiscualitativo.com.ar).

ROMÁN PÉREZ, ROSARIO (2000): Del primer vals al primer bebé. Vivencias del embarazo en las jóvenes. México: SEP-IMJ.

SAltalamaCCHia, Homero (1990) «La juventud hoy: un análisis conceptual». Revista Ciencias Sociales. San Juan: Universidad de Puerto Rico (disponible en http://saltalamacchia.com.ar).

_ (S/F): «La juventud y sus estigmas». En http://saltalamacchia.com.ar. 
Tabla 1: Caracterizaciones

\begin{tabular}{|c|c|c|c|c|c|c|c|}
\hline $\begin{array}{c}\begin{array}{c}\text { Representa- } \\
\text { ciones } \\
(\text { Chaves, 2005) }\end{array} \\
\text { (Ches }\end{array}$ & $\begin{array}{c}\text { Discursos } \\
\text { (Chaves, 2005) }\end{array}$ & $\begin{array}{c}\text { Mitos de la } \\
\text { juventud } \\
\text { homogénea } \\
\text { (monocromá- } \\
\text { tica) } \\
\text { (Braslavsky, } \\
1986 \text { ) } \\
\end{array}$ & $\begin{array}{c}\text { Paradigmas en } \\
\text { las investigacio- } \\
\text { nes } \\
\text { (Saltalamacchia, } \\
2004)\end{array}$ & $\begin{array}{c}\text { Paradigmas } \\
\text { dentro de las } \\
\text { ciencias sociales } \\
\text { (Macri y Van } \\
\text { Kemenade, 1993) }\end{array}$ & $\begin{array}{c}\text { Paradigmas en las } \\
\text { programaciones } \\
\text { para la juventud } \\
(\text { Krauskopf, 2000) }\end{array}$ & $\begin{array}{c}\text { Estigmas } \\
\text { (Cajías, 1999) }\end{array}$ & $\begin{array}{c}\text { Imágenes } \\
\text { (Reguillo, } \\
\text { 2000) }\end{array}$ \\
\hline $\begin{array}{c}\text { Joven como ser } \\
\text { inseguro de sí } \\
\text { mismo }\end{array}$ & \begin{tabular}{|c|} 
Naturalista \\
Psicologista \\
Patología social \\
Pánico moral \\
\end{tabular} & $\begin{array}{l}\text { Juventud } \\
\text { Gris }\end{array}$ & $\begin{array}{l}\text { Juventud } \\
\text { problema }\end{array}$ & Organicistas & $\begin{array}{c}\text { Juventud: } \\
\text { etapa problema }\end{array}$ & $\begin{array}{c}\text { Aquellos originados } \\
\text { en el mundo } \\
\text { conservador }\end{array}$ & \\
\hline $\begin{array}{c}\text { Joven como ser } \\
\text { en transición }\end{array}$ & $\begin{array}{l}\text { Naturalista } \\
\text { Psicologista } \\
\text { Culturalista }\end{array}$ & $\begin{array}{l}\text { Juventud } \\
\text { Dorada }\end{array}$ & $\begin{array}{l}\text { Juventud } \\
\text { problema }\end{array}$ & \begin{tabular}{|c|} 
Organicistas \\
Sociopsicológicas \\
Culturalistas \\
Estructural fun- \\
cionalismo \\
\end{tabular} & \begin{tabular}{|c|} 
Adolescencia: \\
período preparatorio \\
Juventud: \\
etapa problema
\end{tabular} & $\begin{array}{l}\text { Aquellos originados } \\
\text { en el mundo } \\
\text { conservador }\end{array}$ & \\
\hline $\begin{array}{c}\text { Joven como ser } \\
\text { no productivo }\end{array}$ & \begin{tabular}{|c|} 
Patología social \\
Pánico moral \\
Culturalista
\end{tabular} & $\begin{array}{l}\text { Juventud } \\
\text { Dorada }\end{array}$ & $\begin{array}{l}\text { Juventud } \\
\text { problema }\end{array}$ & Culturalistas & \begin{tabular}{|c|} 
Adolescencia: \\
período preparatorio \\
Juventud: \\
etapa problema \\
\end{tabular} & $\begin{array}{l}\text { Aquellos con un } \\
\text { destino focalizado }\end{array}$ & \\
\hline $\begin{array}{l}\text { Joven como ser } \\
\text { incompleto }\end{array}$ & $\begin{array}{l}\text { Naturalista } \\
\text { Psicologista }\end{array}$ & $\begin{array}{l}\text { Juventud } \\
\text { Gris }\end{array}$ & $\begin{array}{c}\text { Juventud } \\
\text { Problema } \\
\text { Receptor pasivo }\end{array}$ & $\begin{array}{l}\text { Organicistas } \\
\text { Culturalistas } \\
\text { Estructural fun- } \\
\text { cionalismo }\end{array}$ & \begin{tabular}{|c|} 
Adolescencia: \\
período preparatorio
\end{tabular} & $\begin{array}{c}\text { Aquellos originados } \\
\text { en el mundo conser- } \\
\text { vador Aquellos } \\
\text { provocados por } \\
\text { políticas de Estado }\end{array}$ & \\
\hline
\end{tabular}




\begin{tabular}{|c|c|c|c|c|c|c|c|}
\hline $\begin{array}{c}\text { Representa- } \\
\text { ciones } \\
\text { (Chaves, } \\
2005)\end{array}$ & $\begin{array}{l}\text { Discursos } \\
\text { (Chaves, } \\
\text { 2005) }\end{array}$ & 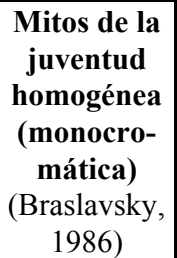 & $\begin{array}{c}\text { Paradigmas } \\
\text { en las investi- } \\
\text { gaciones } \\
\text { (Saltalamac- } \\
\text { chia, 2004) }\end{array}$ & 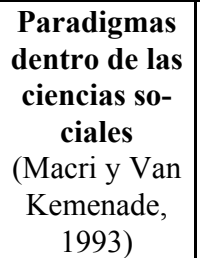 & $\begin{array}{c}\text { Paradigmas en } \\
\text { las programacio- } \\
\text { nes para la ju- } \\
\text { ventud } \\
\text { (Krauskopf, 2000) }\end{array}$ & $\begin{array}{c}\text { Estigmas } \\
\text { (Cajías, 1999) }\end{array}$ & $\begin{array}{c}\text { Imágenes } \\
\text { (Reguillo, 2000) }\end{array}$ \\
\hline $\begin{array}{c}\text { Joven como } \\
\text { ser desinte- } \\
\text { resado y/o } \\
\text { sin deseo }\end{array}$ & \begin{tabular}{|c|} 
Patología \\
social Pánico \\
moral Cultu- \\
ralista
\end{tabular} & $\begin{array}{c}\text { Juventud } \\
\text { Gris }\end{array}$ & $\begin{array}{l}\text { Receptor } \\
\text { pasivo }\end{array}$ & & $\begin{array}{c}\text { Juventud: } \\
\text { etapa problema }\end{array}$ & $\begin{array}{c}\text { Aquellos con un destino } \\
\text { focalizado Aquellos apoya- } \\
\text { dos en su condición de ser el } \\
\text { «otro» }\end{array}$ & \\
\hline $\begin{array}{l}\text { Joven como } \\
\text { ser desviado }\end{array}$ & \begin{tabular}{|c|} 
Patología \\
social \\
Pánico moral \\
Culturalista
\end{tabular} & $\begin{array}{c}\text { Juventud } \\
\text { Gris }\end{array}$ & $\begin{array}{l}\text { Juventud } \\
\text { problema }\end{array}$ & $\begin{array}{c}\text { Estructural } \\
\text { funcionalismo }\end{array}$ & $\begin{array}{c}\text { Juventud: } \\
\text { etapa problema }\end{array}$ & $\begin{array}{c}\text { Aquellos provocados u } \\
\text { originados por un compor- } \\
\text { tamiento juvenil contrario al } \\
\text { «proceso humano» Aquellos } \\
\text { con un destino focalizado } \\
\text { Aquellos provocados por } \\
\text { políticas de Estado }\end{array}$ & $\begin{array}{l}\text { como subversi- } \\
\text { vos (70) como } \\
\text { delincuente y } \\
\text { violento (desde } \\
\text { los } 80)\end{array}$ \\
\hline $\begin{array}{c}\text { Joven como } \\
\text { ser peligroso }\end{array}$ & \begin{tabular}{|c|} 
Patología \\
social Pánico \\
moral Cultu- \\
ralista
\end{tabular} & $\begin{array}{l}\text { Juventud } \\
\text { Gris }\end{array}$ & $\begin{array}{l}\text { Juventud } \\
\text { problema }\end{array}$ & \begin{tabular}{|c|} 
Estructural \\
funcionalismo
\end{tabular} & $\begin{array}{c}\text { Juventud: } \\
\text { etapa problema }\end{array}$ & $\begin{array}{l}\text { Aquellos con un destino } \\
\text { focalizado Aquellos provo- } \\
\text { cados por políticas de Esta- } \\
\text { do Aquellos apoyados en su } \\
\text { condición de ser el «otro» }\end{array}$ & $\begin{array}{l}\text { como subversi- } \\
\text { vos (70) como } \\
\text { delincuente y } \\
\text { violento (desde } \\
\text { los } 80)\end{array}$ \\
\hline $\begin{array}{l}\text { Joven como } \\
\text { ser victimi- } \\
\text { zado }\end{array}$ & Sociologista & $\begin{array}{l}\text { Juventud } \\
\text { Gris }\end{array}$ & $\begin{array}{l}\text { Juventud } \\
\text { problema }\end{array}$ & & $\begin{array}{l}\text { Juventud: etapa } \\
\text { problema Juven- } \\
\text { tud: actor estraté- } \\
\text { gico del desarrollo }\end{array}$ & $\begin{array}{c}\text { Aquellos con un destino } \\
\text { focalizado Etica de la vícti- } \\
\text { ma: mendicidad } \\
\text { y criminalidad. }\end{array}$ & \\
\hline
\end{tabular}




\begin{tabular}{|c|c|c|c|c|c|c|c|}
\hline $\begin{array}{c}\text { Represen- } \\
\text { taciones } \\
\text { (Chaves, } \\
\text { 2005) }\end{array}$ & $\begin{array}{c}\text { Discursos } \\
\text { (Chaves, 2005) }\end{array}$ & 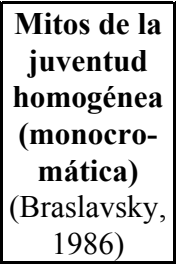 & $\begin{array}{c}\begin{array}{c}\text { Paradigmas } \\
\text { en las investi- } \\
\text { gaciones }\end{array} \\
\text { (Saltalama-c- } \\
\text { chia, 2004) }\end{array}$ & 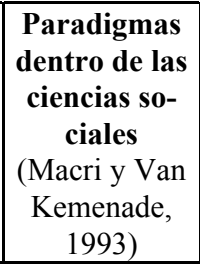 & $\begin{array}{l}\text { Paradigmas en las } \\
\text { programaciones } \\
\text { para la juventud } \\
\text { (Krauskopf, 2000) }\end{array}$ & $\begin{array}{c}\text { Estigmas } \\
\text { (Cajías, 1999) }\end{array}$ & $\begin{array}{c}\text { Imágenes } \\
\text { (Reguillo, 2000) }\end{array}$ \\
\hline $\begin{array}{l}\text { Joven como } \\
\text { ser rebelde } \\
\text { y/o revolu- } \\
\text { cionario }\end{array}$ & $\begin{array}{c}\text { Naturalista Psi- } \\
\text { cologista Sociolo- } \\
\text { gista }\end{array}$ & $\begin{array}{c}\text { Juventud } \\
\text { Blanca }\end{array}$ & \begin{tabular}{|c|} 
Juventud \\
problema \\
Juventud \\
como impulso \\
renovador y \\
como reactor
\end{tabular} & \begin{tabular}{|c|} 
Organicistas \\
Estructural \\
funcionalismo
\end{tabular} & \begin{tabular}{|c|} 
Juventud: etapa pro- \\
blema Juventud: actor \\
estratégico del desa- \\
rrollo
\end{tabular} & & $\begin{array}{c}\text { como rebeldes } \\
\text { (fines de los } 50 \text { y } \\
\text { durante los 60) } \\
\text { como estudiantes } \\
\text { revoltosos (fines } \\
\text { de los 60) }\end{array}$ \\
\hline $\begin{array}{l}\text { Joven como } \\
\text { ser del } \\
\text { futuro }\end{array}$ & $\begin{array}{c}\text { Naturalista Psi- } \\
\text { cologista Sociolo- } \\
\text { gista }\end{array}$ & $\begin{array}{c}\text { Juventud } \\
\text { Blanca }\end{array}$ & & & $\begin{array}{c}\text { Adolescencia: período } \\
\text { preparatorio Juventud: } \\
\text { actor estratégico del } \\
\text { desarrollo }\end{array}$ & $\begin{array}{l}\text { Aquellos origina- } \\
\text { dos en el mundo } \\
\text { conservador Aque- } \\
\text { llos apoyados en } \\
\text { su condición de } \\
\text { ser el «otro» }\end{array}$ & \\
\hline $\begin{array}{l}\text { Joven como } \\
\text { ser en rela- } \\
\text { ción: com- } \\
\text { pleto y } \\
\text { complejo }\end{array}$ & \begin{tabular}{|c|} 
Complejidad: \\
contextual (espa- \\
cial e histórica- \\
mente situado), \\
relacional (con- \\
flictos y consen- \\
sos) y heteroge- \\
neidad (diversidad \\
y desigualdad)
\end{tabular} & $\begin{array}{l}\text { Juventud } \\
\text { multicolor }\end{array}$ & \begin{tabular}{|c|} 
Juventud \\
como impulso \\
renovador y \\
como reactor
\end{tabular} & \begin{tabular}{|c|} 
Contextuales \\
y multidisci- \\
plinarios
\end{tabular} & \begin{tabular}{|c|} 
Juventud ciudadana \\
(aparentemente esta \\
concepción implica \\
una mirada más com- \\
pleja, no se cuenta con \\
trabajos que la anali- \\
cen en profundidad)
\end{tabular} & $\begin{array}{l}\text { Sin estigmatiza- } \\
\text { ciones ni negati- } \\
\text { vas ni positivas }\end{array}$ & $\begin{array}{l}\text { Es pues, de mane- } \\
\text { ra privilegiada, en } \\
\text { el ámbito de las } \\
\text { expresiones cultu- } \\
\text { rales donde los } \\
\text { jóvenes se vuel- } \\
\text { ven visibles como } \\
\text { actores sociales }\end{array}$ \\
\hline
\end{tabular}

